\title{
Evaluation of Free and Total L-Thyroxine in Serum by a Commercial Procedure
}

\author{
M. J. Obregon, ${ }^{1}$ A. Kurtz, ${ }^{2}$ R. Ekins, ${ }^{2}$ and G. Morreale de Escobar ${ }^{1}$
}

We assessed a commercial kit (Corning Medical) for "free" and total thyroxine determination, results being compared to those obtained by the Ekins and Ellis dialysis method (free thyroxine) and the method of Weeke and Orskov (total thyroxine). The kit procedure permits determination of both free and total thyroxine within 4 to $5 \mathrm{~h}$, and the combined results may disclose changes in binding to plasma proteins that would be missed if only free thyroxine were determined.

With both free-thyroxine methods, the values distinguished hyperthyroid patients from normal controls and pregnant women with $100 \%$ accuracy, but there was some overlap between hypothyroid patients and controls. Absolute values with the kit procedure often exceed those obtained by dialysis, especially for hypothyroid patients and pregnant women. We conclude that the kit may be of as much diagnostic value as the dialysis method if the limitations regarding absolute values are kept in mind and the test is not used as a substitute for thyrotropin determinations in cases of suspected hypothyroidism.

\section{Additional Keyphrases: "kit" methods thyroid status}

Circulating thyroxine and triiodothyronine are mostly bound to plasma proteins, and it is generally admitted that the unbound ("free") fractions are more directly related to the metabolic state than is either the total or bound fraction (1, 2). Corning Medical, Medfield, MA 02052, has developed a method for determination of "free" thyroxine $\left(F-T_{4}\right)$ as a result of studies on the kinetics and thermodynamics of the binding of thyroxine to anti- $\mathrm{T}_{4}$ antibodies immobilized on glass particles (3). These studies demonstrated that the rate at which thyroxine adsorbs onto the immobilized antibody is related to the amount of $\mathrm{F}-\mathrm{T}_{4}$, the process being monitored with labeled thyroxine. The most adequate response "metameters" for the calculation of F-T 4 from the raw data obtained with the reagents supplied by Corning Medical have been discussed by Ekins (4) and have been taken into account by the manufacturers.

Here, we report an evaluation of the $\mathrm{F}_{-} \mathrm{T}_{4}$ kit supplied by Corning Medical. We determined that $\mathrm{F}_{-} \mathrm{T}_{4}$ and total thyroxine $\left(\mathrm{T}-\mathrm{T}_{4}\right)$ with the kit and compared results with those obtained by other methods: a dialysis method for $\mathrm{F}_{-} \mathrm{T}_{4}(5)$ and a highly sensitive radioimmunoassay for $T-T_{4}(6)$.

\section{Materials and Methods}

We used a total of 85 samples. None of the 20 healthy volunteers were taking oral contraceptives or had any clinical history of thyroid disease. Twenty samples were obtained from

\footnotetext{
${ }^{1}$ Departamento de Endocrinología Experimental, Instituto G. Marañón, C.S.I.C. y Facultad Autónoma de Medicina, Arzobispo Morcillo, s/n Madrid 34, Spain.

${ }^{2}$ Department of Nuclear Medicine, Middlesex Hospital Medical School, London, U.K.

Received May 9, 1980; accepted Aug. 29, 1980.
}

patients who were clinically thyrotoxic and had high serum triiodothyronine concentrations, 25 from patients who where clinically hypothyroid and had higher than normal circulating thyrotropin concentrations, and 20 from pregnant women.

The samples were collected at the Middlesex Hospital, London. Aliquots were used there to determine F-T 4 by the dialysis procedure (5). T- $\mathrm{T}_{4}$ and $\mathrm{F}-\mathrm{T}_{4}$ were determined in Madrid with the kit reagents provided by Corning Medical, and $\mathrm{T}-\mathrm{T}_{4}$ and total triiodothyronine $\left(\mathrm{T}-\mathrm{T}_{3}\right)$ by previously validated methods $(6,7)$. The code for identification of the samples was broken after we received the data for the F-T 4 determinations carried out at the Middlesex Hospital. The only plasma thyrotropin determinations were those done to confirm previous thyrotropin determinations used for initial diagnosis, and these were done after breaking the code.

In determining $\mathrm{T}-\mathrm{T}_{4}$ and $\mathrm{F}-\mathrm{T}_{4}$ concentrations by the kit procedure we used four of these kits for the 85 sera, the unknown samples being allotted at random to each kit. Some of the samples, also chosen at random, were run in several assays.

Briefly, the assay requires $25-\mu \mathrm{L}$ aliquots of standards of unknowns, pipetted in quadruplicate; two tubes receive a solution containing ${ }^{125}$ I-labeled thyroxine (the A series of tubes) and two the same solution except containing thimerosal as blocker of thyroxine binding to proteins (B series of tubes). After a 30 -min incubation, the anti-thyroxine antibody, immobilized on glass particles, is added. After $30 \mathrm{~min}$, the tubes are centrifuged and the supernates discarded. The radioactivity of the A and B series of tubes (cpm A; cpm B) and of the total radioactivity added $(\mathrm{cpm} T)$ is determined by $1-\mathrm{min}$ counts in an automatic gamma counter.

The cpm B values for the standards are used to plot the $\mathrm{T}-\mathrm{T}_{4}$ standard curve, with use of data supplied by the manufacturers $(13,52,107,210$, and $315 \mathrm{nmol} / \mathrm{L})$. The $\mathrm{T}-\mathrm{T}_{4}$ value and the cpm $A$ values of the standards are used to calculate the response "metameter" $\mathrm{Y}\left[\mathrm{Y}=(\mathrm{cpmA} / \mathrm{cpmB}) \times \mathrm{T}-\mathrm{T}_{4}\right]$, which is plotted against the $\mathrm{F}-\mathrm{T}_{4}$ concentrations supplied by the manufacturers $(6.4,12.8,25.7,51.5$, and $77.2 \mathrm{pmol} / \mathrm{L})$ to obtain the F-T 4 standard curve.

F-T $\mathrm{T}_{4}$ was also determined by the dialysis procedure described by Ekins and Ellis (5). In brief, 200-L aliquots of sera are dialyzed overnight at $4{ }^{\circ} \mathrm{C}$ against $5 \mathrm{~mL}$ of dialysis medium containing sodium azide (not thimerosal) as bacteriostat. The thyroxine in the dialysate is then determined by radioimmunoassay.

T-T 4 and $\mathrm{T}-\mathrm{T}_{3}$ were also determined according to Weeke and Orskov $(6,7)$, with minor modifications introduced by Obregon (8), such as the use of polyethylene glycol instead of wick chromatography to separate free and antibody-bound labeled thyroxine. The very high specific activity of the labeled thyroxine and triiodothyronine obtained in the laboratory $(9$, 10) allows the use of very small serum aliquots, namely $0.5 \mu \mathrm{L}$ per tube and $10 \mu \mathrm{L}$ per tube for $\mathrm{T}-\mathrm{T}_{4}$ and $\mathrm{T}-\mathrm{T}_{3}$, respectively. The radioimmunoassay buffer contains $0.6 \mathrm{mmol}$ of thimerosal, addition of other "blockers" being necessary for T-T 4 . For T-T 3 , 2.37 nmol of 8-anilino-1-naphthalene sulfonic acid is added as "blocker."

We used the kit from Corning Medical to determine serum 
Table 1. Between-Assay Varlation in F-T and T-T $T_{4}$ Values by the Kit Procedure for Two Control Sera

( $C_{1}$ and $C_{2}$, Supplied by the Manufacturer) and Six Unselected Sera

\begin{tabular}{|c|c|c|c|c|c|c|c|}
\hline \multirow[b]{3}{*}{ Sample } & \multirow[b]{3}{*}{$n^{a}$} & \multicolumn{3}{|c|}{ Freo thyroxino } & \multicolumn{3}{|c|}{ Total thyroxine } \\
\hline & & Moan & SD & & Mean & so & \\
\hline & & \multicolumn{2}{|c|}{ pmol/L } & CV, \% & \multicolumn{2}{|c|}{$\mathrm{nmol} / \mathrm{L}$} & CV, $\%$ \\
\hline$C_{1}$ Normal $^{b}$ & 4 & 18.9 & 0.6 & 3.4 & 85 & 8 & 8.6 \\
\hline $\mathrm{C}_{2}$ Normal $^{b}$ & 4 & 36.7 & 1.4 & 3.9 & 158 & 8 & 5.2 \\
\hline Normal & 4 & 19.0 & 1.0 & 5.9 & 99 & 6 & 5.9 \\
\hline Hyperthyroid & 4 & 48.9 & 4.1 & 8.6 & 251 & 14 & 5.4 \\
\hline Hyperthyroid & 4 & 56.9 & 3.1 & 5.5 & 255 & 6 & 2.7 \\
\hline Hypothyroid & 3 & $<6.4$ & - & - & 24 & 5 & 20.9 \\
\hline Hypothyroid & 3 & $<6.4$ & - & - & 32 & 6 & 20.0 \\
\hline Pregnant & 2 & 18.1 & 1.6 & 9.0 & 188 & 10 & 6.9 \\
\hline Pregnant & 2 & 16.1 & 0.9 & 5.7 & 143 & 8 & 5.1 \\
\hline
\end{tabular}

- Number of kits in which the sample was assayed in duplicate.

- Data supplied by the manufacturer for free thyroxine in $C_{1}$ and $C_{2}$ are 17.4 (SD 3.2) and 38.0 (SD 5.8) pmol/L, respectively; for total thyroxine 76 (SD 9 ) and 148 (SD 14) nmol/L, respectively.

\begin{tabular}{|c|c|c|c|c|c|c|c|c|c|}
\hline \multirow[b]{4}{*}{ Controls } & \multirow[b]{4}{*}{20} & \multirow{2}{*}{\multicolumn{4}{|c|}{ Total thyroxino }} & \multicolumn{4}{|c|}{ Free thyroxime } \\
\hline & & \multirow{3}{*}{$\begin{array}{l}\text { Mothod A } \\
112(17)\end{array}$} & & & \multirow{3}{*}{$\begin{array}{r}\text { Ratlo } \\
1.08\end{array}$} & Mothod A & Mothod B & \multirow{3}{*}{$\begin{array}{c}p^{\mathbf{a}} \\
<0.001\end{array}$} & \multirow{3}{*}{$\begin{array}{l}\text { Ratlic } \\
1.33\end{array}$} \\
\hline & & & Mothod B & \multirow{2}{*}{$\begin{array}{c}\mathbf{p}^{\mathbf{a}} \\
<0.001\end{array}$} & & & & & \\
\hline & & & $103(19)$ & & & $19.3(2.4)$ & $15.3(2.8)$ & & \\
\hline Hypothyroid & 25 & $54(26)$ & $29(19)^{b}$ & $<0.001$ & 2.13 & $10.1(3.3)^{d}$ & $6.0(3.1)$ & $<0.001$ & 2.04 \\
\hline Hyperthyroid & 20 & $257(36)^{c}$ & $274(44)$ & $<0.02$ & 0.94 & $60.6(11.3)^{\theta}$ & $75.8(33.0)$ & n.s. & 0.89 \\
\hline Pregnant & 20 & $168(22)$ & $144(31)$ & $<0.001$ & 1.20 & $17.1(4.1)$ & $12.0(3.8)$ & $<0.001$ & 1.63 \\
\hline
\end{tabular}

- $p$ for paired t-test.

- Six of 25 samples had a $T-T_{4}$ value $<13 \mathrm{nmol} / \mathrm{L}$ by Method $B$. For the present calculations they have been assigned a value of $13 \mathrm{nmol} / \mathrm{L}$.

c One of 20 samples had a T-T $T_{4}$ value $>322$ by Method $A$ and was assigned this value for the calculations.

- Three of 25 samples had F-T $T_{4}$ value $<6.4 \mathrm{pmol} / \mathrm{L}$ by Method $A$ and was assigned this value for the calculations.

- Five of 20 samples had F-T 4 values at the upper limit of detection by method A and were assigned a value of 77.2 pmol/L for calculations.

thyrotropin, following the supplier's instructions without modification.

\section{Results}

Using the reagents provided by Corning Medical, we found the radioactivities in duplicate tubes to be almost identical. The standard curves for $\mathrm{F}-\mathrm{T}_{4}$ obtained with the four different kits were almost superimposable. There was a somewhat larger variation in the $\mathrm{T}-\mathrm{T}_{4}$ standard curves in the range corresponding to low $\mathrm{T}_{-} \mathrm{T}_{4}(52 \mathrm{nmol} / \mathrm{L}$, and lower $)$. Table $1 \mathrm{sum}$ marizes between-assay variations we obtained for the two control sera supplied, as well as for six unknown sera chosen at random. The CVs are quite satisfactory for the $\mathrm{F}-\mathrm{T}_{4}$ and T-T $\mathrm{T}_{4}$ values of the sera tested with the four kits, the two samples from hypothyroid patients excepted. ${ }^{3}$

Figure 1 shows results for T-T 4 by both the kit method and the comparison method. Table 2 shows the mean values (and SD) for the different groups of patients and the means of the individual ratios between the values obtained with the two different methods. Nineteen of 20 sera from normal volunteers had a $\mathrm{T}_{4}$ concentration between 77 and $154 \mathrm{nmol} / \mathrm{L}$. All of the 20 samples from hyperthyroid patients had a $T-T_{4}$ concentration exceeding $180 \mathrm{nmol} / \mathrm{L}$ by both methods, several sam-

${ }^{3}$ This may be owing to differences in the $T-T_{4}$ standard curves in the low $\mathrm{T}-\mathrm{T}_{4}$ range; when we used $\mathrm{cpm} \mathrm{B} / \mathrm{cpm} \mathrm{T}$ data obtained for each of the two hypothyroid sera on different occasions, the between-assay CVs were reduced to 1.8 and $2.9 \%$. ples having a $\mathrm{T}-\mathrm{T}_{4}$ near or above the upper limit of detection of the kit method. About $70 \%$ of the 20 sera from pregnant women had a T-T 4 value exceeding $154 \mathrm{nmol} / \mathrm{L}$ with the kit method, whereas with the reference method only $40 \%$ exceeded the normal range.

The major difference between the results obtained by the two methods was for sera from hypothyroid patients. None of them had a T-T $\mathrm{T}_{4}$ value above $77 \mathrm{nmol} / \mathrm{L}$ by the reference method, but with the kit procedure there was some degree of overlap with the normal range, four of 25 samples giving a $\mathrm{T}-\mathrm{T}_{4}$ value above $77 \mathrm{nmol} / \mathrm{L}$, though two of them did not exceed $90 \mathrm{nmol} / \mathrm{L}$. Although in all groups except the hyperthyroid group the $\mathrm{T}_{4}$ value obtained with the kit procedure exceeded that with the reference method (Table 2), the difference was particularly striking in the case of sera from hypothyroid patients.

These relationships are also illustrated in Figure 2, where the individual $\mathrm{T}-\mathrm{T}_{4}$ values obtained with both methods are plotted.

Figure 3 shows the results for $\mathrm{F}-\mathrm{T}_{4}$ by the kit and the dialysis methods. The reported reference interval differs for the two methods: $14.2-32.2$ and $8.5-23.0 \mathrm{pmol} / \mathrm{L}$, respectively. The F- $\mathrm{T}_{4}$ values found for all 20 control sera and 25 sera from hyperthyroid patients fell, respectively, within and above the normal ranges. The $\mathrm{F}-\mathrm{T}_{4}$ values for sera from pregnant women all fell within the reported normal range with the kit method. With the dialysis procedure, one of the 20 sera from pregnant women showed a value below the normal range. With both 


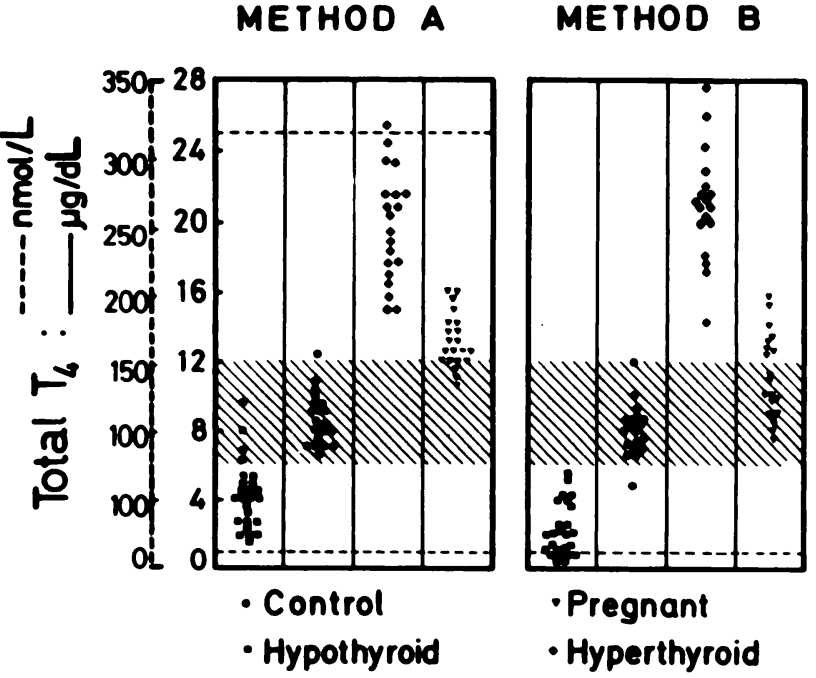

Fig. 1. Total thyroxine $\left(T_{4}\right)$ concentrations in sera from 20 normal controls, 20 pregnant women, 20 hyperthyroid, and 25 hypothyroid patients, as determined by the kit procedure (Method A) and by the method of Weeke and Orskov (Method B, ref. 6)

In this and other figures, the shaded areas represent normal ranges and dotted lines the upper or lower limits of detection with usual sample volumes.

methods, most $\mathrm{F}_{-} \mathrm{T}_{4}$ values for sera from hypothyroid patients fell below the normal range, but there was some overlap with the normal range and with values found for the control sera. This was the case for four sera with use of the kit procedure, one of them having a borderline value, and for six sera by the dialysis method. Three sera giving a F-T 4 value within the normal range with the kit reagents were the same ones that also had a normal $\mathrm{T}-\mathrm{T}_{4}$ and a normal $\mathrm{F}-\mathrm{T}_{4}$ by the dialysis method.

The data obtained with the Corning Medical procedure were higher than those by the dialysis method for all groups except the hyperthyroid one (Table 2). The highest ratios were found for the sera from hypothyroid patients and pregnant women.

Figure 4 shows T-T $_{3}$ values we obtained with the method

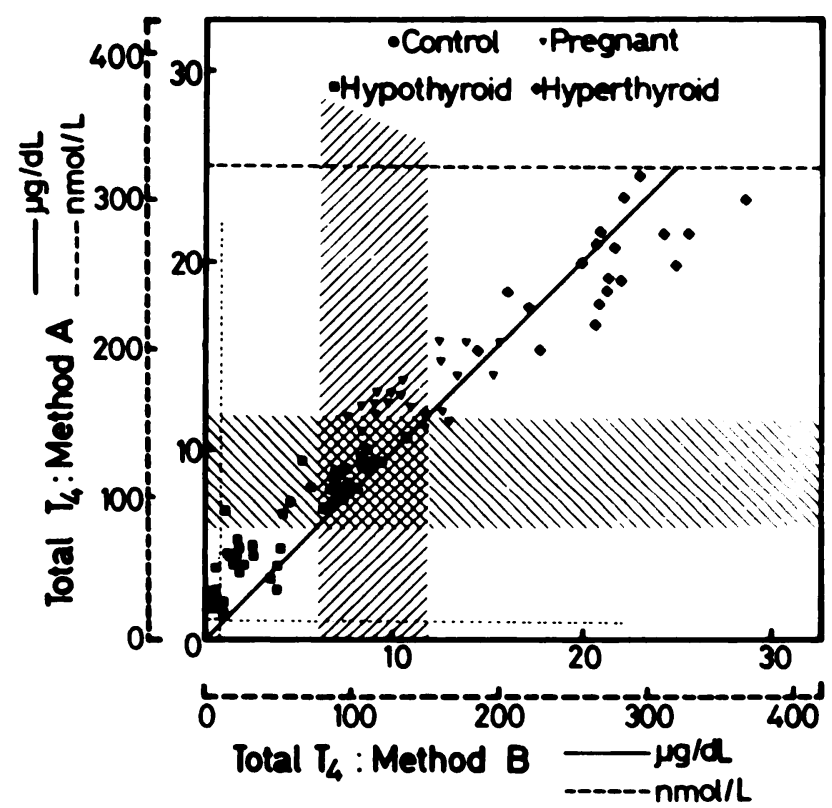

Fig. 2. Total thyroxine concentrations, corresponding to the same samples as for Figure 1: Values obtained by the Medical Corning procedure (Method A) are plotted against those obtained by the method of Weeke and Orskov (Method B)
METHOD A METHOD

B

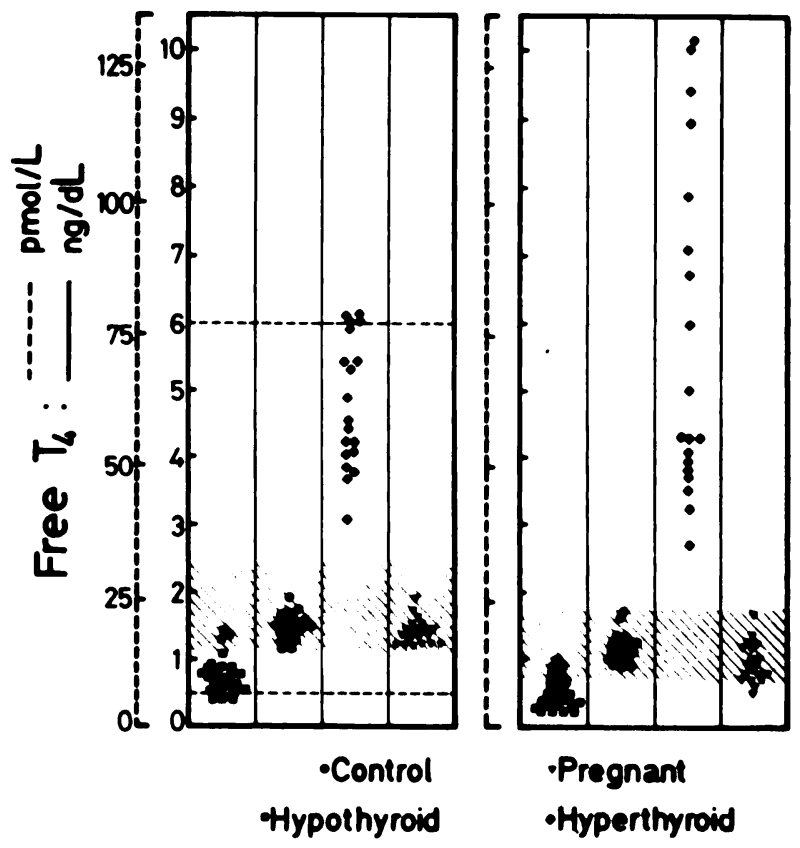

Fig. 3. Free thyroxine concentrations of the same sera as for Figure 1, as determined by the Corning Medical procedure (Method A) and by the dialysis method (Method B, ref. 5)

of Weeke and Ørskov (7), which support the stated diagnosis of the patients. So did the concentrations of thyrotropin in the plasma of the 17 pregnant women tested and of the 25 sera from hypothyroid patients. ${ }^{4}$

\section{Discussion}

The laboratory performance of the kit was quite satisfactory. The procedure is simple, and both the T-T $T_{4}$ and $F-T_{4}$ of a patient are known within 4-5 h. Both values are obtained in a single test, with corresponding simplification of laboratory routine. The combined results for $\mathrm{F}-\mathrm{T}_{4}$ and $\mathrm{T}-\mathrm{T}_{4}$ disclose the presence of changes in binding to plasma proteins, which would be missed on the basis of the $\mathrm{F}-\mathrm{T}_{4}$ data alone.

The standard curves for $\mathrm{F}-\mathrm{T}_{4}$ and $\mathrm{T}-\mathrm{T}_{4}$ obtained with different kits were very similar, except for $\mathrm{T}_{-} \mathrm{T}_{4}$ in the low range. This might be due to excessive spacing of the low $\mathrm{T}-\mathrm{T}_{4}$ standards. ${ }^{5}$ Results obtained with the internal control sera supplied by the manufacturers fell within the reported means \pm 1 SD. Between-assay CVs were satisfactory for sera from normal and hyperthyroid patients, and pregnant women. CVs for the $\mathrm{F}_{-} \mathrm{T}_{4}$ of the two sera from hypothyroid patients could not be calculated and those for the $\mathrm{T}-\mathrm{T}_{4}$ were higher $(\sim 20 \%) .3,5$

With data on both F-T $\mathrm{T}_{4}$ and $\mathrm{T}-\mathrm{T}_{4}$, hyperthyroid patients can be identified and distinguished with $100 \%$ accuracy from normal people and pregnant women, both with the kit and the other methods we used. Diagnostic accuracy of the F-T 4 values was less for the group of 25 hypothyroid patients, both with the kit procedure $(84 \%)$ and the dialysis method $(76 \%)$, as already observed by others (11). Thus, from the present series

${ }^{4}$ The lowest plasma thyrotropin value in the hypothyroid group ( $16 \mu$ units $/ \mathrm{mL}$ ), although well above the normal range given by the manufacturers $(0.2-9.1 \mu$ units $/ \mathrm{mL})$, corresponded to a patient with T- $\mathrm{T}_{4}$ (kit procedure) and $\mathrm{F}-\mathrm{T}_{4}$ (both the kit and the dialysis methods) values well within the normal range.

${ }^{5}$ The manufacturers are aware of this problem and are taking measures to increase the number of standards in the low T.T range. 


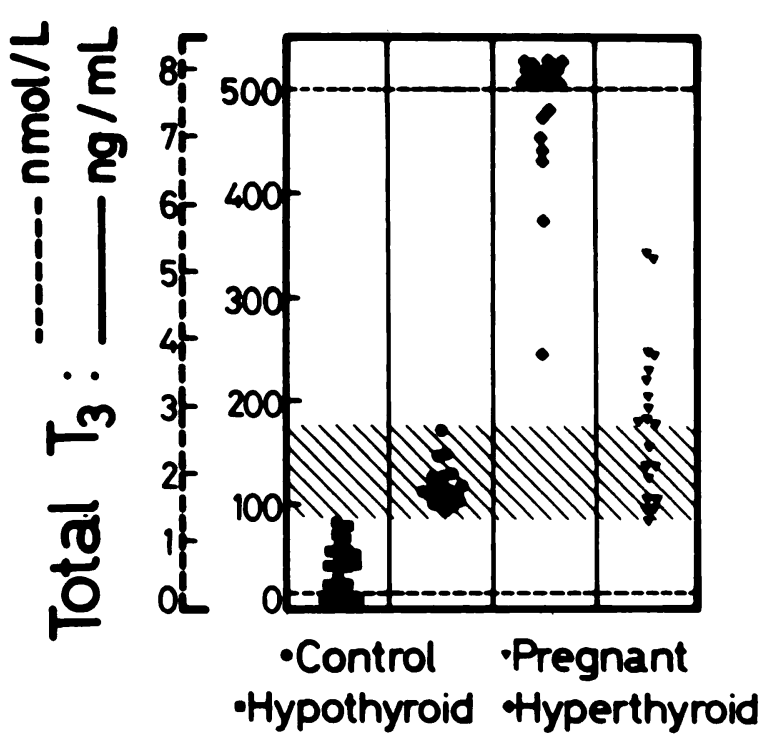

Fig. 4. Total triiodothyronine concentrations of the same sera as for Figure 1, as measured with the method of Weeke and Orskov ( 7 )

of patients, it would appear that the kit method gives at least the same clinical information as that obtained by a well-established dialysis technique, but is simpler to perform, not requiring any more experience than is needed for other routine radioimmunoassays.

However, the diagnostic performance of the T-T $\mathrm{T}_{4}$ and $\mathrm{T}-\mathrm{T}_{3}$ data, as obtained by the methods of Weeke and Ørskov $(6,7)$ was $100 \%$, even in the hypothyroid range. One of the normal controls might have been classified as hypothyroid, on the basis of the $\mathrm{T}-\mathrm{T}_{4}$ value alone, but this diagnosis would have been excluded after determination of thyrotropin, which was normal. However, none of the hypothyroid patients would have been missed on the basis of the $T-T_{4}$ or $T-T_{3}$ data alone.

The absolute values obtained for $\mathrm{F}-\mathrm{T}_{4}$ and for $\mathrm{T}-\mathrm{T}_{4}$ concentrations depend on the method used; this is especially evident for sera from hypothyroid patients and pregnant women. It is impossible at present to know which procedures, if any, give "true" results, i.e., results that represent the actual circulating $\mathrm{F}-\mathrm{T}_{4}$ and $\mathrm{T}-\mathrm{T}_{4}$ concentrations. As pointed out (4), none of the dialysis methods for $\mathrm{F}-\mathrm{T}_{4}$ can be considered as having the status of a reference technique. A possible factor that might increase the $F-T_{4}$ results in the case of the kit procedure and other procedures in which the patient's plasma proteins are present during the radioimmunoassay, is nonspecific binding of the labeled thyroxine tracer, which would be more prominent in sera with low $\mathrm{F}-\mathrm{T}_{4}$ and a larger proportion of unoccupied binding sites (as in hypothyroidism) or in the sera with high thyroxine-binding globulin (as in pregnancy). Such a factor might also contribute to overestimation of the $\mathrm{T}-\mathrm{T}_{4}$ in these groups, despite addition of a standard amount of thimerosal. An overestimation of the T-T might further influence the $F-T_{4}$ value, because the $T_{4}$ value is used for calculation of the response "metameter" $Y$. The dialysis procedure (5) would be free from such a potential source of error in the case of the $\mathrm{F}-\mathrm{T}_{4}$ determinations. The method of Weeke and $\emptyset$ rskov (6), because a very small serum sample is required, $0.5 \mu \mathrm{L}$, would minimize it in the case of T-T 4 .

The technical assistance of Ms. S. Durán and Mr. von Borcke is gratefully acknowledged, as is the financial support from Corning Medical, who provided the kits and reagents and covered extra expenses for equipment, laboratory and personnel.

\section{References}

1. Robbins, J., and Rall, J. E., The interaction of thyroid hormones and proteins in biological fluids. Recent Prog. Horm. Res. 13, 161-208 (1957).

2. Ingbar, S. H., and Freinkel, N., Regulation of the peripheral metabolism of thyroid hormones. Recent Prog. Horm. Res. 16, 353-404 (1960).

3. Hertl, W., and Odstrchel, G., Kinetic and thermodynamic studies of antigen-antibody interactions in heterogeneous reaction phases. Mol. Immunol. 16, 173-178 (1978).

4. Ekins, R., Commercial radioimmunoassay for free thyroxine. Lancet i, 1190-1191 (1979).

5. Ekins, R., and Ellis, R. P., The radioimmunoassay of free thyroid hormones in serum. In Thyroid Research, J. Robbins, and L. E. Braverman, Eds., Excerpta Medica Found., Amsterdam, 1975, pp $597-600$.

6. Weeke, J., and Ørskov, K., Evaluation of thyroid function. In Recent Aduances in Clinical Biochemistry, 1, K. G. M. Alberti, Ed., Churchill Livingstone, London, 1978, pp 111-128.

7. Weeke, J., and Ørskov, K., Ultrasensitive radioimmunoassay for direct determination of free triiodothyronine concentration in serum. Scand. J. Clin. Lab. Invest. 35, 237-244 (1975).

8. Obregón, M. J., Hormonas tiroideas circulantes y en tejidos: Estudio de sus concentraciones por radioimmunoanalisis. Ph.D. thesis, Faculty of Chemistry, Universidad Autónoma, Madrid, 1978.

9. Weeke, J., and Ørskov, K., Synthesis of ${ }^{125}$ I monolabeled 3:5:3' triiodothyronine and thyroxine of maximum specific activity for radioimmunoassay. Scand. J. Clin. Lab. Invest. 32, 357-360 (1973).

10. Kjeld, J. M., Kuku, S. K., Diamant, L., et al., Production and storage of ${ }^{125}$ I-thyroxine and ${ }^{125}$ I-triiodothyronine of high specific activity. Clin. Chim. Acta, 61, 381-389 (1975).

11. Yeo, P. P. B., Lewis, M., and Evered, C., Radioimmunoassay of free thyroid hormone concentrations in the investigation of thyroid disease. Clin. Endocrinol. 6, 159-165 (1977). 